\title{
WestVirginiaUniversity
}

THE RESEARCH REPOSITORY @ WVU

Graduate Theses, Dissertations, and Problem Reports

2011

\section{Associations between co-parenting, parenting stress, and military deployment}

\author{
Brittane L. Todd \\ West Virginia University
}

Follow this and additional works at: https://researchrepository.wvu.edu/etd

\section{Recommended Citation}

Todd, Brittane L., "Associations between co-parenting, parenting stress, and military deployment" (2011). Graduate Theses, Dissertations, and Problem Reports. 4805.

https://researchrepository.wvu.edu/etd/4805

This Thesis is protected by copyright and/or related rights. It has been brought to you by the The Research Repository @ WVU with permission from the rights-holder(s). You are free to use this Thesis in any way that is permitted by the copyright and related rights legislation that applies to your use. For other uses you must obtain permission from the rights-holder(s) directly, unless additional rights are indicated by a Creative Commons license in the record and/ or on the work itself. This Thesis has been accepted for inclusion in WVU Graduate Theses, Dissertations, and Problem Reports collection by an authorized administrator of The Research Repository @ WVU. For more information, please contact researchrepository@mail.wvu.edu. 


\title{
ASSOCIATIONS BETWEEN CO-PARENTING, PARENTING STRESS, AND MILITARY DEPLOYMENT
}

\author{
by \\ Brittane L. Todd \\ Thesis submitted to the College of Human Resources and Education \\ at West Virginia University \\ in partial fulfillment of the requirements for the degree of
}

Master of Arts

in

Educational Psychology with an emphasis in Child Development and Family Studies

\author{
Approved by \\ Amy E. Root, Ph.D, Committee Chairperson \\ Kristin Moilanen, Ph.D, Member \\ Jessica Troilo, Ph.D, Member \\ Department of Technology, Learning, and Culture \\ Morgantown, West Virginia \\ 2011
}

Keywords: co-parenting, parenting stress, deployment, military

Copyright 2011 Brittane L. Todd 


\section{Abstract \\ ASSOCIATIONS BETWEEN CO-PARENTING, PARENTING STRESS, AND MILITARY DEPLOYMENT}

\section{by Brittane Todd}

The purpose of this study was to examine the differences in parenting stress and parenting alliance following a military deployment as a function of the level of coparenting exhibited during deployment. Two co-parenting groups (high and low) were formed based on co-parenting practices during the deployment. A total of 31 participants comprised the sample $($ High $=16$ and Low $=15)$ and completed the anonymous online surveys including The Co-Parenting Scale, the Parenting Alliance Measure, and the Parenting Stress Index-Short Form. The groups did not differ in the levels of parenting alliance. Additionally, the low co-parenting group did not report significantly greater parenting stress following deployment when compared to the high co-parenting group. However, post-hoc analyses did indicate that the low co-parenting group reported greater parent-child dysfunctional interaction following deployment. This finding, while not significant, may indicate a subset of the population that may be at a greater risk for parenting stress. Future studies should be replicated with a larger sample size. 


\section{Acknowledgements}

I would like to take the time to thank all of my committee members for their guidance and support throughout the thesis process. First and foremost, my advisor, Dr. Amy Kennedy-Root has been such a positive mentor for me the past couple of years and I am truly grateful for her expertise and patience with me throughout my Graduate career. In addition, I would like to thank Dr. Jessica Troilo and Dr. Kristin Moilanen for their constructive criticisms and encouragement while completing my thesis. I am so lucky to have such positive mentors to look up to and learn from while completing my Masters degree.

Furthermore, I would like to thank all of my CDFS girls for the constant support and encouragement over the years. I definitely needed the continuous reminders of "you can do this!” from my friends in the program. I have formed many lasting bonds that I know will go way beyond college and I am so grateful for these lasting friendships. Additionally, through my GA position at the WVU Nursery School I have gained firsthand experience working with children and families. I am so appreciative of the support from my co-workers including Bobbie, Melissa, Diana, Keri, and Kaitlin. I have so many fond memories working with all of you and I am truly going to miss you!

Last but not least, I would like to take the time to thank my amazing family and boyfriend, Adam, for the unconditional love and support throughout my college (6 year) experience. Without a doubt, I know that I would not be where I am today without their support and encouragement. I love you all. THANK YOU!!! 


\section{Table of Contents}

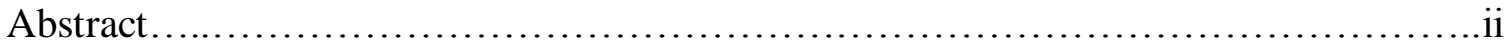

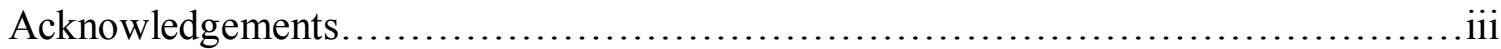

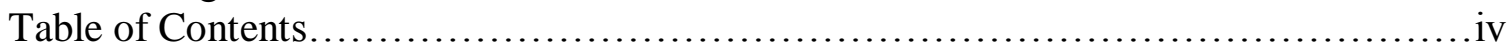

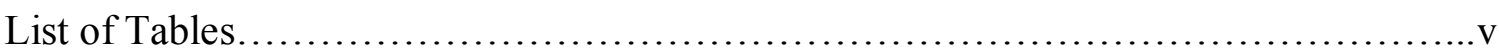

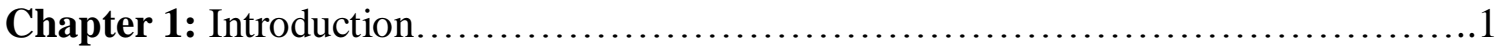

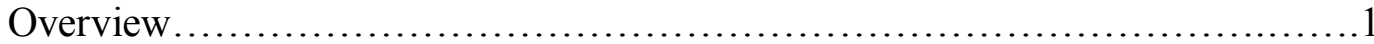

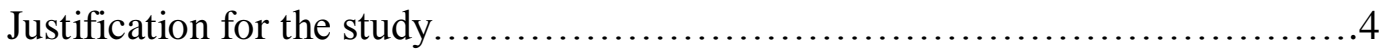

Statement of the problem.................................................. 4

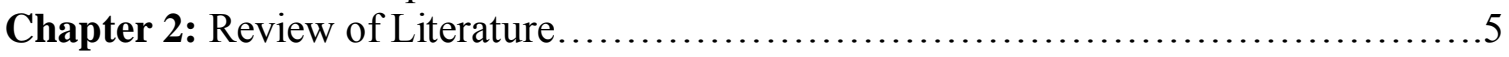

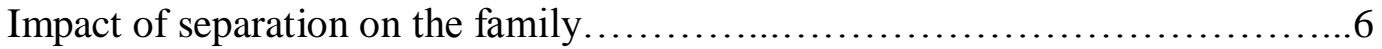

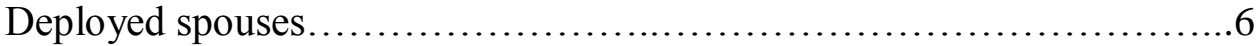

Stateside spouses................................................ 8

How the separation affects the parenting process............................ 14

Studies of families long term separation............................... 14

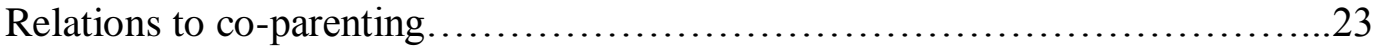

Co-parenting and its significance in family functioning..................24

Hill's (1949) Families under Stress Perspective.................................27

Purpose and Hypotheses .................................................. 30

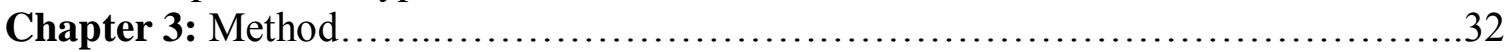

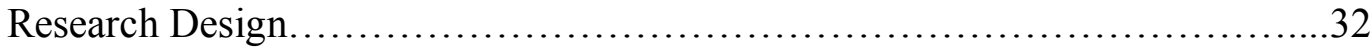

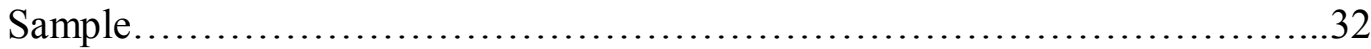

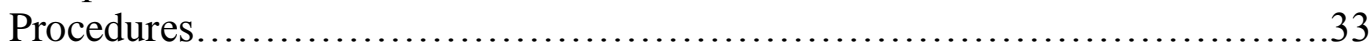

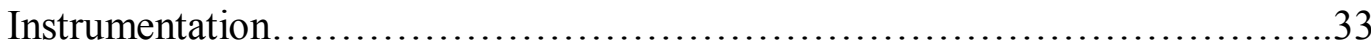

Background/Demographics Questionnaire..........................33

The Co-parenting Scale..............................................34

Parenting Stress Index-Short Form....................................34

Parenting Alliance Measure.......................................... 35

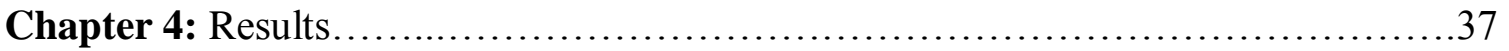

Parenting Alliance Measure .................................................. 37

Parent Stress Index-Total................................................... 37

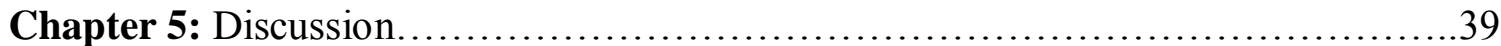

Limitations and Future Directions........................................44

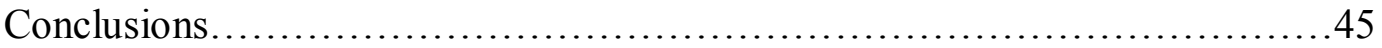

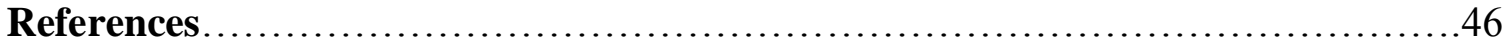

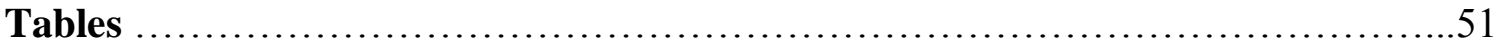

Table 1: Means and Standard Deviations......................................51

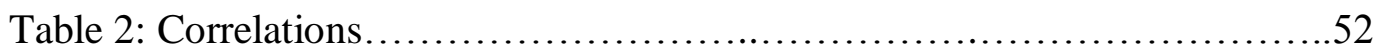

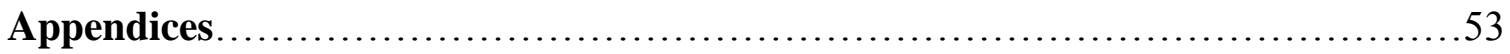

Appendix A: Background/Demographics Questionnaire......................53

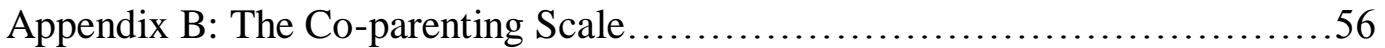

Appendix C: Parenting Stress Index-Short Form............................5 57

Appendix D: Parenting Alliance Measure ....................................61 


\section{List of Tables}

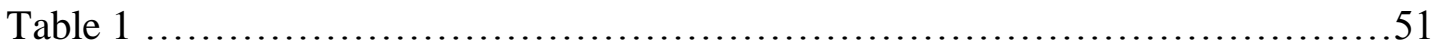

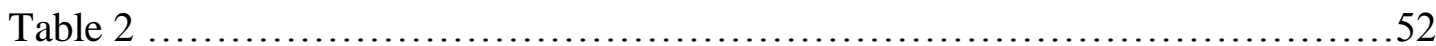




\section{Chapter 1: Introduction}

\section{Overview}

In the past researchers have investigated family stress and how stress impacts the family unit (Hill, 1949). Some stressors placed on the family unit throughout daily life include career obligations, marriage, and birth of a child. Indeed, stress placed on the family unit impacts individual families in unique ways depending on how each family member perceives the stressor and chooses to manage this stress (Hill, 1949). Specific family processes, such as parenting and childrearing practices, may help to alleviate or exacerbate the level of stress and disruptions within the family during a time of difficulty (Allen, Rhoades, Stanley, \& Markman, 2010; Bowling \& Sherman, 2008; Doyle \& Peterson, 2005; Faber, Willerton, Clymer, MacDermid, \& Weiss, 2008; Mmari, Roche, Suhinaraset, \& Blum, 2009).

Although war and the impacts of war on families is not a new field of study, after the events of September 11, 2001, researchers began to reinvestigate the effects of deployment on military families. These families are often cycling through a period of stress or trauma throughout the deployment cycle. The primary source of stress for military families is separation (Hill, 1949), however military families experience challenges throughout the entire deployment cycle which includes pre-deployment, during the deployment period, and throughout the reintegration period (i.e., when the family is reunited; Allen et al., 2010; Bowling \& Sherman, 2008; Doyle \& Peterson, 2005; Faber et al., 2008; Kelley, Herzog-Simmer, \& Harris, 1994; Mmari et al., 2009; Sahlstein, Maguire, \& Timmerman, 2009). Moreover, stress seems to impact the entire family unit, including the deployed spouse (Kelley et al., 1994; Newby et al., 2005; 
Wadsworth, 2010), the stateside spouse, and the family members who remain home during deployment (Henderson, 2008; Sahlstein et al., 2009; SteelFisher, Zaslavsky, \& Blendon, 2008; Warner, Appenzeller, Warner, \& Grieger, 2009). Thus, it should not be surprising that stress has been found to impact the parenting process in military families (Allen et al., 2010; Bowling \& Sherman, 2008; Doyle \& Peterson, 2005; Faber et al., 2008; Mmari et al., 2009).

In this growing area of study, it has been documented that deployed spouses report negative consequences of deployment such as increased levels of parenting stress and anxiety (Kelley et al., 1994). Furthermore, the impacts of military deployment on the family members left stateside indicate that the separation poses additional stressors to the stateside spouse including challenges facing parenting responsibilities alone (e.g., managing finances, or disciplining the children; Henderson, 2008; Sahlstein et al., 2009; SteelFisher et al., 2008), and decreased mental well-being (SteelFisher et al., 2008; Warner et al., 2009). Researchers have also indicated that parental figures experience role ambiguity (Faber et al., 2008; Mmari et al., 2009) and adjustment challenges (Bowling \& Sherman, 2008; Doyle \& Peterson, 2005) before, during, and after deployment. Further, previous studies examining parenting stress reveal that increased levels of parenting stress leads to poor parenting practices and increased levels of emotional and behavioral problems in children (Abidin, 1992; Assel et al., 2002; Guajardo, Snyder, \& Peterson, 2009). Given the impact on the entire family unit and the parenting process, it seems that further research is warranted in this area.

As aforementioned, families experiencing military deployment face challenges throughout the entire deployment cycle, not just while the family member is deployed. 
Most of the research focuses on families pre-deployment and during deployment as opposed to the reintegration period (i.e., the time following deployment). However, researchers are beginning to acknowledge the amount of stress and readjustments families experience even after their deployed individual has returned home (Allen et al., 2010; Bowling \& Sherman, 2008; Mmari et al., 2009; Sahlstein et al., 2009). Following deployment, families are forced to once again renegotiate individual roles and reestablish boundaries. For example, while the mother may have solely carried out parenting roles while the father was deployed, once the father returns, the couple has to readjust parenting responsibilities (Doyle \& Peterson, 2005).

It seems likely that some families may adjust more smoothly after deployment than others, and it may be that parenting practices during deployment impact the reintegration period. One specific parenting process that is known to play a pervasive role in the success of the family unit is co-parenting. Co-parenting refers to at least two individuals effectively working together to support each other in the childrearing process, including the division of labor, establishing rules and routines, and mutually agreeing on goals and values for raising the children (McHale et al., 2002; McHale, Kuersten-Hogan, \& Rao, 2004; Van Egeren \& Hawkins, 2004). There is empirical evidence for the benefits of building strong co-parenting partnerships in order to increase children's social and emotional development (McHale et al., 2002), and decrease behavioral problems in school-aged children (McConnell \& Kerig, 2002). Given the literature on the benefits of co-parenting, it may be that military families who have strong co-parenting alliances would face fewer disruptions post-deployment and thus co-parenting could mitigate the effects of deployment on the family unit. 


\section{Justification for the Study}

Although previous researchers have investigated the impacts of long-term separation on the deployed individual, the stateside spouse, and the parenting process in general, no studies have examined co-parenting in a military population. Furthermore, no studies have examined the specific associations between co-parenting during deployment and levels of stress and parenting alliance post-deployment. This area of study will provide information that is ripe with opportunity for translation to the applied setting. Specifically, it seems by better understanding the benefits of co-parenting during deployment it would "open the door" for the development of prevention and intervention programs for military families facing deployment, as well as help identify ways to help families during deployment and post-deployment. This research study aimed to close the gap in literature by examining the relations between co-parenting alliances and parenting stress in a military sample. With the knowledge of the associations between these factors, military families may be able to reduce or work towards limiting the amount of parenting stress experienced throughout the deployment cycle by building and maintaining strong co-parenting bonds.

\section{Statement of the Problem}

The purpose of this investigation was to examine the differences in parenting stress and parenting alliance post deployment depending on the level of co-parenting during deployment. Specifically, families who recalled high levels of co-parenting practices during deployment were compared to families who recalled low levels of coparenting practices during deployment on their reported parenting stress and co-parenting alliance following deployment. 


\section{Chapter 2: Review of Literature}

The family unit faces several stressors throughout the family life cycle (Hill, 1949). Typical family stressors may be exacerbated within military families due to longterm separation as a result of deployment. In today's society, several men and women serve their country by joining the military and face long-term separation from their families. Specifically, according to the Department of Defense, in September of 2010, over 1 million people served in the United States military. This raises the question: how does deployment impact the family unit?

There is empirical support indicating that deployment causes major disruptions in the family unit (Wadsworth, 2010). Specifically, long-term separations impact how each family member functions (including their roles and responsibilities) as well as how the family unit functions together (Wadsworth, 2010). For example, Wadsworth (2010), found that challenges faced by the deployed person may fall into three categories: physical (e.g., duration, workload, injuries), psychological (e.g., family worries, exposure to trauma), and moral (e.g., soldiers do not always agree with the reasons for the United States' involvement in the war). On the other hand, challenges faced by the family members left stateside tend to be either psychological (e.g., worry, loneliness), logistical (e.g., communication with partner, responsibility of household needs), or economic (e.g., paying bills; Wadsworth, 2010). Thus, it is clear that deployment stresses the military couple.

Given that there appears to be an increase in stress within military families (Newby et al., 2005), it seems important to examine which aspects of military life heighten family stress and to investigate ways to minimize these stressors. For one, the 
parenting relationship between spouses before, during, and after deployment likely contributes to the ways in which individuals manage family stress. Thus it seems plausible that individuals who exhibit greater co-parenting alliances (i.e., parenting where partners work together to raise their children) during deployment may handle family stressors following deployment in more positive ways; however there is no empirical literature on the benefits of the co-parenting process within military families who face deployments. Therefore, the purpose of this investigation was to examine how coparenting practices during deployment impact post-deployment stress and parenting in military families. Specifically, I compared families who report high and low coparenting practices during deployment on their reported parenting stress and co-parenting alliance following deployment.

\section{Impact of Separation on the Family}

Deployed Spouses. Researchers have demonstrated that deployment takes its toll on deployed individuals, and it appears that separation from family is a significant stressor for soldiers. For instance, Newby and colleagues (2005) investigated the positive and negative consequences of military deployment, and addressed the stressors faced by Army families experiencing extended and multiple deployments. In this study, Newby et al. (2005) examined the soldiers of a peacekeeping deployment to Bosnia and responded to surveys about their perceptions of positive and negative consequences of deployment. A little over half of the sample $(n=519)$ was married and $(n=432)$ were not married, with the majority of the participants being men (Newby et al., 2005). Married soldiers were more likely to report negative consequences of deployment, such as being away from home or deterioration of marital relationships when compared to single soldiers 
(Newby et al., 2010). Moreover, separation from family and missing important events was reported as the most negative consequence for married soldiers. As a result, it appears that separation from family during this time increases stress on the deployed individual.

In addition, individuals anticipating an upcoming deployment exhibit increased levels of stress concerning their role as a parent. Kelley et al. (1994) examined the effects of military-induced separation on deploying mothers and found that stress predeployment impacts family functioning. In this study, Kelley et al. (1994) examined parenting attitudes, parenting behaviors, childrearing practices, stress, and anxiety in a sample of military mothers. The sample comprised a pre-deployment group and a reunion group (mothers who have previously been deployed); and all participants completed a battery of questionnaires, including an assessment of perceptions of stress (Parenting Stress Index; Abidin, 1990), anxiety associated with deployment (Maternal Separation Anxiety Scale; Hock, McBride, \& Gnezda, 1989), dimensions of parenting (i.e. sensitivity and consistency; Parenting Dimensions Inventory; Power, 1991), and overall functioning of the family unit (Family Environment Scale; Moos \& Moos, 1981). When Kelley et al. (1994) compared the deploying group to the reunion group, they found that mothers anticipating deployment reported higher levels of parenting stress and child stress than mothers following deployment. Furthermore, deploying mothers reported that their children exhibited higher levels of difficult behaviors prior to deployment (Kelley et al., 1994). Conversely, reported levels of parenting stress in the reunion group were not impacted by deployment which Kelley et al. (1994) suggested was due to mothers' previous experiences with deployment and the fact that they have already faced and 
overcome these stressors. Therefore, individuals anticipating an upcoming deployment for the first time experience parental stressors and disruptions to the family unit.

Thus, it seems clear that parents who face deployment have increased levels of stress, which may impact their parenting behaviors. Deploying parents express concerns not only regarding their specific needs and worries, but also the needs of their children. Overall, deployed parents worry about missing important events (Newby et al., 2010), being separated from their loved ones for so long (Kelley et al., 1994), and exhibit concerns regarding the everyday functioning of their family (i.e., roles and routines; Wadsworth, 2010).

Inevitably, these negative consequences experienced by married soldiers also impact parenting by the stateside spouse. For instance, when a deployed parent misses his or her child's birthday, the stateside spouse is left to help the child cope emotionally and not feel neglected by his deployed parent on this special occasion. Therefore, in the following section I will discuss the impact of deployment on the stateside spouse.

Stateside Spouses. Similar to the effects of deployment on the deployed individual, research also acknowledges the stress deployment places on the stateside spouse. Many individuals facing long-term separation from their spouses inevitably encounter parenting challenges (Henderson, 2008). Stateside spouses have the sole responsibility of disciplining their children and managing their households. Essentially, deployment can make all stateside spouses feel like and assume the behaviors of single parents.

Stressors impacting the stateside spouse may be exacerbated if the family faces multiple deployments and these stressors can ultimately impact the mental health of the 
stateside spouse. Warner et al. (2009) studied psychological effects of deployment on military families and found that some of the major family stressors include problems communicating, raising children without the other spouse present, and balancing work and family responsibilities. Warner et al. (2009) also investigated how demographic factors, such as number of deployments, and how different stressful experiences impacted depressive symptoms of the stateside spouse. Participants included 295 primarily female spouses of soldiers in a deploying Army Brigade Combat Team. Stateside spouses completed a series of questionnaires and surveys as their spouses prepared and left for deployment (Warner et al., 2009). Stateside spouses were asked to rate a variety of deployment stressors (e.g., loneliness, having problems communicating with their spouse, raising a young child while their spouse is not present) and perceived barriers to receiving psychological care based on Schumm et al. (1996) (e.g., family members might view them differently or it would be too embarrassing to seek help).

Furthermore, stateside spouses completed the Perceived Stress Scale (PSS; Cohen \& Williamson, 1988) to measure their perceived levels of stress within the past month related to events that were out of their control (e.g., "How often have you felt that you were unable to control the important things in your life?"; Warner et al., 2009). The Patient Health Questionnaire 9 (PHQ-9; Kroenke, Spitzer, \& William, 2001) was also administered to assess the participants' current levels of depression rated on a scale of mild, moderate, moderate-severe, or severe (Warner et al., 2009). Ultimately, Warner et al. (2009) found that different deployment stressors may lead to more serious problems within the family unit. Specifically, perceived stress led to increased risk for depression, and almost half of the participants met the criteria for depression (Warner et al., 2009). It 
is clear that deployment negatively impacts the psychological well-being and stress levels of the stateside spouses. Thus, it seems necessary to understand what family processes, such as co-parenting, may minimize stress in the stateside spouses.

Correspondingly, SteelFisher et al. (2008) examined the impacts of deployment on stateside spouses. They compared couples who experienced deployment extensions (i.e., longer separations than originally expected) to couples who did not face extensions. Specifically, SteelFisher et al. (2008) investigated stateside spouses' perceptions of deployment on their general well-being, challenges with daily life, and their overall feelings towards the Army. Respondents consisted of 798 stateside Army spouses who answered questions via an anonymous telephone survey assessing their perceptions of problems with deployment such as health, mental well-being, and challenges with relationships (e.g., How often have you had the feelings of loneliness?, Do you think your husband's/wife's deployment had a positive or negative impact on your health?; SteelFisher et al., 2008). According to SteelFisher et al. (2008), the greatest perceived negative impact of deployment was on overall mental well-being, with $78.2 \%$ of the total sample (i.e., spouses who experienced extensions and spouses who did not face extensions) reporting loneliness, $51.6 \%$ experiencing anxiety, and $42.6 \%$ exhibiting depression. Furthermore, the greatest challenge for the stateside spouses in regards to maintaining daily life was communicating with their deployed spouse (40.9\%) (SteelFisher et al., 2008). Thus, it is clear that deployment is a major stressor for the stateside spouses, as well as a potential risk factor for psychopathology. Moreover, the findings of SteelFisher et al. (2008) seem to indicate that stateside spouses' desire for their spouses to be included in the parenting process during separation (as indicated by 
the frustration with communication challenges). These findings underscore the importance for better understanding how deployment impacts parents in order to minimize the parenting challenges couples face associated with deployment.

In a similar investigation utilizing the relational dialectics perspective, Sahlstein et al. (2009) investigated 50 Army wives' (31 of which were mothers) perspectives and experiences regarding the long-term separation from their spouses and newfound parenting independence. The relational dialectics perspective refers to individuals working through contradictions that emerge throughout a relationship (e.g., opposing needs or desires within the relationship; Sahlstein et al., 2009). Respondents participated in in-depth interviews recalling their personal experiences pre-deployment, during deployment, and post-deployment which allowed the interviewers to identify contradictions and coping patterns throughout the deployment cycle (Sahlstein et al., 2009).

Sahlstein and colleagues' (2009) study revealed three themes of major contradictions: uncertainty-certainty during pre-deployment (e.g., period of time when the stateside spouse was unsure of when the husband would deploy, how she would manage his responsibilities in his absence, and trying to regain a sense of confidence in the future), autonomy-connection during deployment (e.g., role struggles and maintaining a long-distance relationship), and openness-closedness during reunion (e.g., spouses struggling with what information to share with each other regarding their experiences throughout separation). As aforementioned, Sahlstein et al. (2009) reported that Army wives indicated that the most salient contradiction pre-deployment is what they labeled "uncertainty-certainty." For instance, stateside spouses expressed their concerns about 
how they were going to manage finances, whether or not their spouses would return safely, or if their spouses would be different people when they returned home (Sahlstein et al., 2009). During this time, stateside spouses would cope with the uncertainties through denial practices by either supporting their husbands or distancing themselves in the relationship (Sahlstein et al., 2009). Moreover, Sahlstein et al. (2009) observed greater levels of certainty among those Army wives who had experienced more than one deployment. In particular, these wives expressed their abilities to positively cope with deployment and viewed their marriages as a cooperative partnership with set roles and expectations (Sahlstein et al., 2009).

Secondly, Sahlstein et al. (2009) found that during the actual deployment, the Army wives struggled with autonomy and connection. Specifically, they struggled with parental roles and separation from their deployed spouse. Stateside spouses had to readjust their parenting strategies in order to play the role of both parents (Sahlstein et al., 2009). Additionally, stateside spouses were forced to negotiate these roles with their children. For example, in one family, the son believed that he needed to take on the roles of his father while his father was away, however, the mother believed these were her responsibilities during this time (Sahlstein et al., 2009).

Lastly, Sahlstein et al. (2009) addressed challenges following deployment including openness and closedness. Certainly couples struggle with communication throughout the entire deployment cycle, but couples struggled with what to share or not share with their partner regarding their experiences following deployment. For example, couples shared their experiences of a "second honeymoon" following deployment in which they did not want to argue or upset each other and just enjoyed being back together 
with each other (Sahlstein et al., 2009). In addition, one spouse stated that she did not want to hear about all the experiences that put her husband in danger while he was deployed (Sahlstein et al., 2009). The findings of Sahlstein et al. (2009) underscore the amount of stress placed on the stateside spouse during deployment, stress that could impact the parenting and co-parenting process. Sahlstein and colleagues (2009) argued that it is important for couples to acknowledge and work through these contradictions as they occur in order to prevent further build up of negative feelings as a result of ignoring these contradictions, which requires communication and negotiation of parenting roles. For example, Sahlstein et al. (2009) believed that if spouses get used to their newfound independence of parenting roles during deployment, and if they do not discuss or renegotiate parenting roles prior to the return of the deployed individual, they may experience greater challenges during reintegration.

In sum, stateside spouses experience a variety of challenges and adjustments when their parenting partner is deployed. These individuals are forced to adjust to new parenting roles, daily routines, and living as a "single parent" for an extended period of time (Warner et al., 2009). Parenting is stressful when committed parenting partners are together through the process, but parenting is greatly impacted if one partner is physically separated from the family. For example, if a child is acting out (i.e., exhibiting delinquent behavior) while the father is absent, the mother is left to manage the behavior alone while her spouse is deployed. Moreover, the father may want to express his authority in trying to correct the misbehavior, but it is difficult for him to follow through with his parenting actions because he is physically separated from his family. During this time, stateside spouses may express their concerns regarding parental role shifts and 
increased levels of stress and depend on extended family members to support them for the duration of the deployment. Furthermore, other individuals reached out to during this stressful time may step in as parental figures in the absence of the real parent. As evidenced above in Warner et al. (2009) and SteelFisher et al.'s (2008) studies, greater stress placed on the stateside spouses can lead to additional challenges faced by the parenting figures.

\section{How the Separation Affects the Parenting Process}

Studies of Families Long Term Separation. Even though there are no studies directly examining co-parenting processes in military families facing deployment, it may be beneficial to explore parenting practices of individuals facing long-term separation from a parenting figure due to incarceration. This is a relevant body of literature to include because much like deployed parents, incarcerated parents struggle with learning how to parent from a distance, although the nature of the separation is qualitatively different. In general, the literature suggests that incarcerated parents report similar parenting challenges as deployed parents. For instance, Eddy et al. (2008) developed a parent training program for incarcerated parents. In the development of this program, Eddy et al. (2008) collected information directly from incarcerated parents about their perceived challenges in parenting. After speaking with parent inmates, Eddy et al. (2008) reported many parenting concerns and needs for the program that are similar to parenting concerns of individuals facing military deployment. For instance, challenges faced by parents included parenting from a distance (e.g., jail or deployment) and maintaining communication with their children and parenting partner (e.g., writing letters or speaking on the phone; Eddy et al., 2008). In addition, similar to challenges faced during the 
reintegration period following deployment, parent inmates expressed concerns with transitioning back to the community and parental roles following their incarceration period. Thus, it seems that one can draw from the literature on parenting in families when one parent is incarcerated when studying co-parenting in military families.

In one of the few studies that has examined parenting during incarceration, Modecki and Wilson (2009) examined associations between the parenting styles of incarcerated fathers by focusing on the participant's educational attainment, length of time incarcerated, and the number of women with whom the participant had children. Specifically, Modecki and Wilson (2009) predicted that longer incarceration time would be associated with decreased responsive (i.e., warm and supportive) and restrictive (i.e., controlling) parenting styles due to fewer opportunities for the incarcerated father to fulfill parental roles and obligations (Modecki \& Wilson, 2009). Participants included 50 incarcerated African American fathers who completed questionnaires and interviews assessing parenting practices utilizing the discipline section of the Parenting Dimensions Inventory (PDI; Slater \& Power, 1987; Modecki \& Wilson, 2009). During the interviews, participants received different parenting case scenarios, such as what they would do if their child deliberately disobeyed them, and they responded with what parenting actions they would take (Modecki \& Wilson, 2009). Modecki and Wilson (2009) found that length of time spent incarcerated and the number of women with whom the participant had children (e.g., 3 children with 3 different women vs. 1 child with 1 woman) were negatively associated with responsive parenting and positively associated with restrictive parenting practices. Specifically, longer incarceration periods and the more women that the participant had a child with were associated with less responsive parenting and higher 
restrictive parenting styles. This study provides evidence that time spent apart from their children impacts parenting practices. Similar to the findings of Modecki and Wilson's (2009) study, length of military deployment and the number of deployments may further impact parenting practices. In turn, individual parenting practices may also influence coparenting alliances. Specifically, parents utilizing responsive parenting may be more likely to maintain communication with their parenting partner and work towards strengthening co-parenting practices during this time of separation.

Indeed, deployed parents are similar to incarcerated parents when considering unique challenges these individuals face regarding maintaining open communication with their families during this period of separation. Further, as a result of minimal visitation sessions during incarceration, incarcerated parents lack authority to make decisions regarding their children (Tuerk \& Loper, 2006), an issue that may be relevant to deployed individuals. In their study of incarcerated mothers, Tuerk and Loper (2006) investigated how the amount of time these individuals spent with their children before incarceration and how the frequency and different types of communication modes (i.e., letters, phone calls, visits) they used during incarceration were associated with parental stress. Tuerk and Loper (2006) predicted that mothers who had daily contact with their children prior to incarceration would continue to communicate with their children during incarceration. In addition, Tuerk and Loper (2006) hypothesized that mothers who had greater contact with their children prior to incarceration would also experience less parental stress. Participants included 357 incarcerated mothers who completed the Parenting Stress Index for Incarcerated Women (PSI-IW; Houck \& Loper, 2002) to assess the participant's parental role motivation and investment, the participant's confidence in making parental 
decisions and disciplining, as well as evaluating the participant's stress associated with the lack of control of visitation of their children while incarcerated (Tuerk \& Loper, 2006). Findings indicated that mothers who communicated with their children frequently during incarceration experienced less parental stress than mothers who did not maintain frequent communication. As a result, communication during separation may mitigate the levels of parental stress during separation.

These results lend support for the importance of maintaining open communication with family members and perhaps strong co-parenting alliances during periods of longterm separation. Within military families, it is important for family members to maintain an open line of communication with their deployed parent in order for the deployed parent to maintain a part of the family unit. Consequently, this allows the deployed parent, much like the incarcerated parent, to feel a sense of belonging and authority within the co-parenting relationship regardless of physical separation.

As indicated in the empirical work on the parenting practices of incarcerated individuals, physical separation of a parent from his or her family inevitably impacts the parenting process (Eddy et al., 2008; Modecki \& Wilson, 2009; Tuerk \& Loper, 2006), and -in turn- likely the co-parenting process. Whether individuals are separated from their families as a result of military deployment or incarceration, these individuals face many similar parenting challenges (Eddy et al., 2008). These parenting figures especially struggle with learning how to be a parent from a distance. Specifically, these unique parenting situations possess communication challenges and further struggles when the individual transitions and returns to the family unit (Eddy et al., 2008; Tuerk \& Loper, 2006). As evidenced in the studies previously discussed, building and maintaining strong 
co-parenting alliances during separation increases marital quality, parenting satisfaction, children's positive adjustment behaviors, and provides overall smoother transitional periods (Ippolito et al., 2010; McConnell \& Kerig's, 2002; McHale et al., 2002). Coparenting processes are an overall integral part of maintaining positive supportive family units during long-term separations.

Although co-parenting is not specifically addressed in the literature focusing on military parents and incarcerated parents, many co-parenting practices can be impacted by these unique experiences. For example, both incarcerated individuals and deployed individuals face challenges learning how to parent from a distance. Communication modes, such as letters and phone calls, may help these parents manage existing parenting challenges. In particular, individuals who maintain open communication during separation are still able to keep in contact with their family's daily lives (Tuerk \& Loper, 2006). Ultimately, by sustaining relationships and being an important part of their family unit throughout separation, parents may limit their anxieties and concerns about returning to their parental roles and responsibilities when they return to their families following deployment or incarceration. Inevitably, parenting stress as a result of long-term separation may be reduced by building and maintaining strong co-parenting relationships during separation.

As evidenced by the studies reviewed above, deployment is a major stressor for all members of military families. As a result of increased stressors placed on both partners, deployment inevitably influences parenting practices. Most of the studies investigating how the separation affects parenting focus mainly on role ambiguity (e.g., uncertainty of role responsibilities, such as disciplining the kids or paying bills; Faber et 
al., 2008) and the newfound independence of each partner (e.g., freedom to make childrearing decisions on their own; Bowling \& Sherman, 2008). What seems lacking is an understanding of how the co-parenting process (i.e., spouses working together to parent their children) is impacted throughout the deployment cycle, regardless of physical distance. Spouses face parental role and responsibility shifts when experiencing deployment, but must still work together to effectively parent their children during this time.

As aforementioned, the majority of the extant literature has focused on role shifts that occur during deployment in military families; while this literature is not on coparenting per se, it provides some suggestions about how the parenting process for individual parents may be impacted by deployment. For instance, Mmari et al.'s (2009) qualitative study explored the issues that adolescents and families faced when a parent was deployed. Through semi-structured focus groups and interview sessions conducted with military youths, military parents, and military school-based personnel, Mmari et al. (2009) found that one of the most difficult changes during parental deployment included shifts in family roles and responsibilities. If a father is sent to war, the mother may have to take on the roles normally taken care of by the father in his absence. These increased roles and responsibilities placed on the stateside spouse may cause role strain and stress on the individuals left stateside. Furthermore, during deployment, parenting styles change in order for the parent left stateside to accommodate both the mother and father's parenting role (Mmari et al., 2009); however during the reintegration period, the stateside spouse has to give up the sole parenting responsibility and once again share those parenting roles with the returning spouse. 
Additional evidence for changes to the parenting process that occur during deployment has been gathered primarily via qualitative designs. For one, Faber et al. (2008) examined boundary ambiguity in a sample of 34 spouses, parents, and reservists who have returned from Iraq. Seven semi-structured interviews were conducted at 3, 4, 6, 12, 24, 36, and 52 weeks following return from deployment (Faber et al., 2008). Spouses reported that they had to take over the roles of the deploying parent, in addition to the responsibilities that they already had. Thus, the parent left behind suddenly became a "single-parent" having to make parenting decisions on their own, which likely increased their stress. In addition, parents reported that once the parent returned from deployment, the family had to readjust and re-establish parenting roles and responsibilities, which was another stressor for the family unit. Indeed, the families still experienced boundary ambiguity (Faber et al., 2008). Deployment impacts parenting through shifts and adjustments in parental roles and responsibilities that continues even after deployment. During the transitional period of the deployed spouse returning to the family unit, stateside spouses feared placing too much parental responsibility on the returning spouse in case he or she was not ready to jump right back into the parenting role (Faber et al., 2008). On the other hand, the returning spouse may feel intimidated taking back their previous parental duties for fear of interrupting the new family routine (Faber et al., 2008). Thus, it seems that if parenting partners worked together and communicate to establish new individual parenting expectations, they could circumvent some of the disruptions in the parenting process that occur during the reintegration period.

There is some evidence (beyond that of Faber et al., 2008) that illustrates that, contrary to popular belief, there is further stress when the family is reunited post- 
deployment. Specifically, when the deployed parent returns, additional challenges arise. For example, Mmari et al. (2009) described adolescents' successful adjustment to the parenting style of the stateside spouse, but following return of the deployed parent, adolescents experienced confusion as to which rules to follow: the old family rules (predeployment) or the new family rules (post-deployment). Further, adolescents became accustomed to the rules and routines set by the stateside parents, but when the other parents returned from deployment, the adolescents have to readjust to the rules and parenting style of the parents returning to the family (Mmari et al., 2009). Therefore, family members may experience greater stress during this period of readjustment.

During the reintegration period (i.e., time following deployment), returning soldiers and family members experience a variety of other adjustment challenges. For example, returning soldiers may be affected psychologically by experiencing posttraumatic stress disorder (PTSD). Allen et al. (2010) explored relationships between recent deployment, PTSD, and different marital aspects including dedication to each partner, parenting alliance, and confidence in the marriage. Allen et al. (2010) hypothesized that PTSD symptoms would be related to poorer marital quality. The sample consisted of 434 active duty U.S. Army couples who completed a variety of selfreport measures. Allen et al. (2010) utilized the Parenting Alliance Inventory (PAI; Abidin \& Brunner, 1995) to assess the degree to which the couple perceived themselves to be in a mutually respectful, cooperative, and communicative parenting relationship to care for their children. The PAI highlights the importance of teamwork and collaboration between the spouses. Allen et al. (2010) found that husbands who had recently been deployed exhibited increased levels of PTSD symptoms, which in turn, decreased 
parenting alliance, dedication to the spouse, and confidence in the marriage. Although this study includes a population with a diagnosed mental illness, it lends support for the notion that the parenting process is impacted by deployment. The psychological effects of deployment on returning soldiers may negatively impact parenting following deployment.

Further evidence for the effects of deployment on parenting was acknowledged by Bowling and Sherman (2008). Specifically, in their review, they discussed family roles following deployment, including redefining roles and expectations, managing emotions, building intimacy in relationships, and generating shared meanings of the deployment process. According to the authors, family roles and division of labor have to be renegotiated after the deployed parent returns home (Bowling \& Sherman, 2008). This may be a stressful time for families because the parent left at home has developed a new normalcy in routines and responsibilities, and may have a hard time giving up their new roles when their spouse returns home (Bowling \& Sherman, 2008). Parenting is impacted because individuals have to readjust to collaboratively working together again to parent their children while under the same roof. These spouses no longer face parenting challenges in regards to physical separation, but experience additional parenting challenges with learning how to co-parent while both parents are present in the household. According to Bowling and Sherman (2008), establishing a shared sense of meaning of the deployment process may reduce stress and lead to increased family cohesiveness.

Thus, the period following deployment is one of adaptation and readjustments. This stressful time greatly impacts and influences the parenting process. Indeed, 
deployment of a parent places numerous stressors on the deployed spouse, the stateside spouse, the children, and the overall parenting process. These stressors occur throughout the entire deployment cycle including pre-deployment, during deployment, and postdeployment.

The literature has shown that stress caused by deployment greatly impacts the entire family, as well as the parenting process (Bowling \& Sherman, 2008; Faber et al., 2008; Mmari et al., 2009). Open communication throughout deployment may contribute to positive negotiations re-establishing parenting roles. For example, individuals who maintain communication during deployment and discuss the stateside spouses' parenting roles while the deployed spouse is away, as well as discuss both the stateside spouses' and the deployed spouses parenting roles following deployment, may experience smoother transitions during the reintegration period. Indeed empirical works highlight the importance of acknowledging the different stressors placed on the deployed individual, the stateside spouse, and the children (Faber et al., 2008; Kelley et al., 1994; Mmari et al., 2009; Newby et al., 2005; Sahlstein et al., 2009; SteelFisher et al., 2008; Warner et al., 2009), however it may be important to focus on co-parenting and how maintaining cooperative parenting relationships may positively impact the effects of deployment on the entire family unit. Specifically, strong co-parenting alliances during deployment may reduce parenting stress during and following deployment.

\section{Relations to Co-Parenting}

Parenting stress inevitably impacts the parenting process (Bowling \& Sherman, 2008), and likely impacts co-parenting, as well. Co-parenting refers to a strong, supportive parenting bond in which both parenting figures work together to effectively 
parent their children (McHale et al., 2002). Co-parenting alliances are strengthened when individuals are "on the same page" with parenting and childrearing practices. The ways in which stress impacts co-parenting may depend on the strength, or lack thereof, of the co-parenting bond.

Furthermore, stressors placed on the parenting figures may create challenges in building and maintaining strong co-parenting alliances (McHale et al., 2004; Van Egeren \& Hawkins, 2004). In particular, if both parents experience stress as a result of military deployment, they may be less likely to collaboratively work together during this time. This may be added to the difficulty parents have working together due to logistical constraints imposed by deployment (i.e., proximity, communication; Sahlstein et al., 2009; SteelFisher et al., 2008).

Thus it would seem that co-parenting during deployment would depend on open communication between spouses, although it may be difficult for spouses to communicate during this time. For example, stateside spouses may go days or even weeks without talking to their deployed spouse. This may create challenges in making sure that the deployed spouse is included in childrearing actions and informed about family experiences stateside. It is important for couples to build co-parenting alliances prior to deployment in order to successfully sustain these relationships during and following separation. Moreover, co-parenting alliances may contribute to reduce parenting stress during deployment as well as following deployment.

\section{Co-parenting and Its Significance in Family Functioning. Co-parenting}

broadly refers to two individuals working together and supporting each other in the childrearing process (McHale et al., 2002; McHale et al., 2004; Van Egeren \& Hawkins, 2004). 
This could include both partners agreeing to disciplinary actions for their children, dividing childrearing labor, setting rules, establishing consistent routines, and trusting and supporting each partner to uphold these parenting practices (Feinberg, 2003; McHale et al., 2002). Furthermore, the strength of co-parenting alliances also depends on how parental figures act when they are alone with their child to either support and validate their co-parenting partner or undermine their actions (McHale et al., 2004). For example, a couple may exhibit a weak co-parenting alliance if while the father is away, the mother speaks badly about the father to their child and disputes his parental actions (McHale et al., 2004). Additionally, McHale et al. (2004) found that positive co-parenting can even occur in families in which both parenting figures do not live together, similar to those families experiencing long-term separation as a result of deployment. Individuals effectively co-parent when they demonstrate a collaborative partnership between two parenting figures, establish consistent rules and routines, and provide a safe environment for their children (McHale et al., 2002). Moreover, McHale et al. (2004) acknowledged the fact that parenting figures who demonstrate true co-parenting alliances not only agree on the same childrearing values and goals, but they follow through with their parenting actions. Therefore, strong co-parenting practices may enhance the overall well-being of the family unit.

Furthermore, literature acknowledges the benefits of co-parenting. For instance, when compared to parents who do not agree with each other, parents who work together and are on the same page are more likely to provide a safe environment for their children (McHale et al., 2002). Since most of the literature suggests the fact that co-parenting can 
enhance children's social and emotional development (see McHale et al., 2002 for relevant review), it is vital for parents to strengthen their co-parental alliances.

Indeed, strong co-parenting alliances enhance the overall family climate, but they can also benefit various child outcomes such as behavioral problems. For instance, McConnell and Kerig (2002) investigated the association between co-parenting processes and adjustment in school-aged children. Particularly, McConnell and Kerig (2002) predicted that unsupportive co-parenting practices would relate positively to child maladjustment regarding internalizing (depression, anxiety) and externalizing (aggression) behaviors. The sample included 67 parenting couples and their oldest child ranging from 7- to 11- years old (McConnell \& Kerig, 2002). Parents (both mothers and fathers) and children separately completed a variety of questionnaires, and then parents' co-parenting practices were observed by researchers during family play in which the participants were asked to complete a task together (McConnell \& Kerig, 2002). The participants responded to self-report measures assessing co-parenting, marital adjustment, and children's adjustment (McConnell \& Kerig, 2002). Findings of McConnell and Kerig's (2002) study indicated that there was a positive association between co-parenting practices and school-aged children's adjustment behaviors. For example, higher levels of unsupportive co-parenting practices were associated with higher levels of maladjustment, including depression and more aggressive behaviors of school-aged children (McConnell \& Kerig, 2002). Furthermore, McConnell and Kerig's (2002) findings provide initial evidence of supportive co-parenting practices positively correlated to marital stability. This study further acknowledges the importance of building and maintaining strong, collaborative parenting partnerships in supporting children's overall development. Co- 
parenting alliances not only provide support for the parenting figures themselves, but the well-being of their children as well.

Given the empirical evidence on the benefits of co-parenting, it may be especially important for military families to co-parent during deployment. As an increased number of parents spend more time physically separated from their children on account of military deployment, it is beneficial for parenting figures to establish and maintain positive co-parental alliances. In other words, parents need to maintain open communication regarding family problems or accomplishments during separation. It is important for both parents to be included in the childrearing practices in order to effectively raise successful children. Technological advances such as emails, phone calls, and webcams may help facilitate open communication between the parenting figures that is necessary in order for them to co-parent.

\section{Hill's (1949) Families under Stress Perspective}

Given the literature reviewed, it appears that separation will strain the family unit. Thus, a study examining co-parenting in military families may best be supported via Hill's (1949) perspective of families under stress, focusing on adjustment to the crisis of war separation and reunion.

Hill's (1949) perspective focuses on the impact of stress on the family unit. Specifically, Hill (1949) classified different types of family crisis as "dismemberment (i.e., loss of family member), or accession (i.e., addition of unprepared for member) and demoralization (i.e., loss of morale and family unity)" (p. 10). A family crisis as a result of military deployment would encounter a combination of these crisis categories when the spouse is deployed (e.g., dismemberment), then when the deployed spouse returns 
(e.g., accession), and while re-establishing family roles and routines during deployment and following deployment (e.g., demoralization). Thus, it seems that Hill's (1949) perspective outlines the impacts of how co-parenting practices during these crises may be influenced throughout the deployment cycle.

Moreover, Hill (1949) described a cycle that the family unit undergoes during a period of stress. According to Hill (1949), during a crisis, families experience periods of disorganization, reorganization, and recovery, although each family unit faces unique experiences during this time (Hill, 1949). One could argue that couples experiencing separation due to military deployment may experience this cycle of adjustment twice throughout the deployment. For example, once a couple is informed about an upcoming military deployment, co-parenting figures may experience disorganization in regard to how they are going to maintain co-parenting bonds during the separation, including role and responsibility shifts, as well as maintaining open lines of communication (Kelley et al., 1994; SteelFisher et al., 2008; Wadsworth, 2010; Warner et al., 2009). The stateside spouse undergoes a period of reorganization and recovery during the deployment when he or she takes on the role of both parent figures and establishes new daily routines (Sahlstein et al., 2009; SteelFisher et al., 2008; Warner et al., 2009). Couples then experience a second cycle of adjustment during the reintegration period of deployment. For instance, couples again face disorganization when deployed spouses return home and the stateside spouses routines and independence are disrupted (Allen et al., 2010; Bowling \& Sherman, 2008). Thus, co-parenting figures experience reorganization and recovery post-deployment when couples are forced to renegotiate parenting roles and reestablish daily routines (Bowling \& Sherman, 2008; Mmari et al., 2009). 
Furthermore, Hill (1949) discussed how family structure impacts the ways in which different families manage stress and crisis. For example, in an adult-centered (i.e., two-headed) family, both parents make mutual decisions regarding finances and childrearing practices (Hill, 1949). In this instance, as a result of separation during war, the family may face greater challenges readjusting to daily life in the father's absence (Hill, 1949). In the current study, high and low co-parenting practices, similar to those practiced in Hill's (1949) adult-centered families, were examined to determine how levels of co-parenting during military separation resulted in different levels of parenting stress and co-parenting practices following deployment.

Indeed, there is theoretical support for the link between stress and parenting. For example, Abidin (1992) believed that parenting stress is directly linked to parenting behavior, with greater parenting stress contributing to dysfunctional parenting. There is considerable support for Abidin's (1992) theory and several studies have indicated that parenting stress is associated with maladaptive parenting outcomes. For instance, Guajardo et al. (2009) examined associations between parenting stress and parenting practices. Guajardo et al. (2009) predicted that high parenting stress would be negatively associated with parenting behaviors. Participants included 83 parents who completed self-report measures assessing parenting behaviors, parenting stress, as well as parentchild interactions were observed; the parenting practices included were overreactivity (e.g., harsh verbal commands and physical discipline) and laxness (e.g., submitting to child demands; Guajardo et al., 2009). As expected, parenting stress was associated with dysfunctional parenting behaviors including overreactivity and laxness (Guajardo et al., 
2009). Thus, increased levels of parenting stress among military couples experiencing a deployment may be associated with weak co-parenting bonds.

In a similar study examining the effects of parenting stress on parenting behaviors, Assel et al. (2002) investigated the longitudinal association between maternal stress and parenting practices. Specifically, Assel et al. (2002) hypothesized that greater maternal stress would be directly related to negative parenting behaviors. Participants included 292 mothers of three-year-old children (Assel et al., 2002). Mothers completed selfreport measures assessing their current emotional stress and were observed completing daily activities to assess parenting behaviors (e.g., maternal responsiveness or restrictiveness). As expected, higher emotional stress was associated with lower levels of maternal warm responsiveness (Assel et al., 2002). Furthermore, in support of Abidin's (1992) model, the study by Assel et al. (2002) exhibited support for the notion that high parenting stress was linked to more negative parenting practices.

Thus, in the current study we acknowledged the relationship between parenting stress and parenting practices in utilizing Hill's (1949) families under stress perspective to guide this study on co-parenting in families experiencing parenting stress related to military deployment. As evidenced in the studies described above (see Allen et al., 2010; Bowling \& Sherman, 2008; Mmari et al., 2009; Sahlstein et al., 2009), families who have experienced the deployment of a parent/spouse face challenges and stressors associated with the long-term separation in which Hill's (1949) theory would help to understand how these families cope with the stressors of deployment and possible ways to minimize the stress during this time such as through co-parenting.

\section{Purpose and Hypotheses}


The purpose of this research study was to compare parents who rated themselves as high or low in co-parenting practices during deployment on parenting alliance and parenting stress post-deployment. Previous research suggests that stress negatively influences the family unit (Hill, 1949). Specifically, military deployment raises several additional family stressors such as role ambiguity and shifts in individual family members responsibilities (Faber et al., 2008; Mmari et al., 2009; Sahlstein et al., 2009). No studies to date have investigated the importance of co-parenting bonds during and following military deployment, and how these co-parenting alliances may help to reduce parenting stress as a result of long-term separation. To address these research questions, two groups were formed including a high co-parenting during deployment group and a low co-parenting during deployment group. Furthermore, two main hypotheses were explored. First, it was expected that the low co-parenting group during deployment would express less parenting alliance post-deployment when compared to the high coparenting during deployment group. Second, it was expected that the low co-parenting group during deployment would exhibit greater parenting stress post-deployment when compared to the high co-parenting during deployment group. 


\section{Chapter 3: Method}

\section{Research Design}

In this study, a quantitative research design was employed. Specifically, two groups (i.e., high and low co-parenting groups during military deployment) were compared on the following dependent variables: parenting stress and co-parenting alliance following deployment. Participants included the spouses of deployed individuals and were in the reintegration period in which their deployed spouse has returned home to the family.

\section{Sample}

A total of 39 participants, who remained anonymous throughout the entirety of the study, completed the survey. Eight cases were excluded from data analyses for the following reasons: 4 cases were excluded because they reported that their spouse had not been deployed; 3 cases were excluded because they did not have at least one biological child with their deployed spouse; and 1 case was excluded because their spouse was currently deployed. As a result, the final sample comprised of a total of 31 female participants (mean age $=35)$ who were predominantly Caucasian $(30$ Caucasian; 1 Biracial) and most (58\%) lived in the South Atlantic region of the U.S. as defined by the 2000 United States Census Bureau (Division 5). The majority of participants had completed at least some college $(n=30)$ and half were employed outside of the home $(n$ =16). Participants were restricted to parents who have experienced military deployment of their spouse and have at least one biological child.

Of the 31 participants, the majority indicated their spouse was in the Army (58\%) and $58 \%$ indicated that their spouse returned from deployment within the last 12 months; 
all but six participants indicated that they had experienced multiple deployments. The participants reported about their biological children (13 male, 18 female); the age of the children ranged from 2 months to 29 years.

\section{Procedures}

In order to obtain the sample and to solicit their participation, the study was approved as exempt by the Institutional Review Board (IRB). Following approval from the IRB, participants were recruited via flyer advertisements, including Comcast Channel 3, listservs, and contacts throughout surrounding areas.

Participants were directed to a website where they obtained additional information about the study, gave consent, and anonymously completed the questionnaires (described below). Participant names and contact information were not linked to any of the questionnaires in order to maintain anonymity. As an incentive for completing the surveys, participants received instructions for how to enter a drawing to receive one of three gift cards valued at twenty-five dollars each at the end of the study.

After 31 participants completed the questionnaires, two groups (high and low coparenting) were formed. Specifically, those who reported co-parenting practices during deployment above the $50^{\text {th }}$ percentile were considered the high co-parenting group $(n=$ 16) and those who reported co-parenting practices below the $50^{\text {th }}$ percentile were classified as the low co-parenting group $(n=15)$.

\section{Instrumentation}

Background/demographic questionnaire. Each participant completed an anonymous background/demographics questionnaire (see Appendix A) regarding each participant's age, gender, ethnicity, household income, length of spouse's military 
deployment, branch of military that their spouse is in, length of time since spouse has returned from deployment, number of biological children, and ages of biological children. This measure was used to assess generalizability of the sample and ensure that participants met the proper qualifications for the purposes of this study (i.e., military spouse has returned from deployment and they have at least one biological child). If participants did not meet the requirements, their data was not used.

The co-parenting scale. The Co-parenting Scale (McHale, 1997; see Appendix B) is a 16-item questionnaire used to assess parents' overt and covert co-parenting practices utilized within the family. The Co-parenting Scale incorporates four distinct factors indicating family integrity, disparagement, conflict, and reprimand (McHale, 1997). Respondents reported their frequency of co-parenting activities including promoting family collaboration and cohesion (McHale, 1997) on a 7-point Likert scale ranging from 1 (Absolutely Never) to 7 (Almost Constantly). A co-parenting aggregate was computed by summing the results of four co-parenting questions from the scale (e.g., "how often in a typical week, when you are alone with your child, do you say something to your child about the parenting dyad or family triad or group?", "make a comment to enhance this child's mental image of your absent partner?", “make a remark to invoke or include the absent parent?", "make a comment about your partner that might create a somewhat negative feeling state in your child?") to form the high and low co-parenting groups. This yielded good internal consistency utilizing Cronbach's alphas $(\alpha=.70)$.

Parenting stress index- short form (PSI/SF). The PSI/SF (Abidin, 1995; see Appendix C) is a 36-item self-report measure assessing stress associated with parenting and includes three subscale components: Parental Distress (PD), Parent-Child 
Dysfunctional Interaction (P-CDI), and Difficult Child (DC) (Abidin, 1995). PD

measures the amount of distress the parent experiences related to his or her parenting role, such as experiencing conflict with the parenting partner (Abidin, 1995). P-CDI assesses perceptions regarding the child meeting parenting expectations, and whether or not the parent-child interactions are reinforcing his or her parenting role (Abidin, 1995). DC determines the child's behavioral characteristics that are easy or difficult for the parent to manage (Abidin, 1995). Respondents used a 5-point Likert scale, ranging from Strongly Agree ( $S A)$ to Strongly Disagree $(S D)$, to report the degree to which they agreed with the statement. Sample statements included "I often have the feeling that I cannot handle things very well" and "I feel trapped by my responsibilities as a parent." Cronbach's alpha scores for the scale indicated good reliability $\alpha=.94$ (PSI/SF-Total), $\alpha=.79$ (PSI$D C), \alpha=.89(P S I-C D I), \alpha=.91(P S I-P D)$.

Parenting alliance measure (PAM). Each respondent was administered the PAM (Abidin \& Brunner, 1995; see Appendix D) to assess their degree of parenting alliance with their spouse following deployment. The PAM was first developed and called the Parenting Alliance Inventory (PAI) by Abidin and Brunner (1995) and then later renamed the Parenting Alliance Measure (PAM) (Konold \& Abidin, 2001). A strong parenting alliance is present when both parenting figures are involved in the child's life, value each other's parenting involvement, respect the childrearing goals of the other, and openly communicate with each other (Abidin \& Brunner, 1995). The PAM is a 20 -item self-report measure that assessed the degree to which parenting partners of children ages 1 to 19 cooperated and committed to childrearing practices (Abidin \& Brunner, 1995; Konold \& Abidin, 2001). The PAM assessed two main parenting 
dimensions including communication and teamwork (PAM-CTM), and respect (PAMFROP) (Konold \& Abidin, 2001). Sample statements included "When there is a problem with our child, we work out a good solution together" (i.e., communication and teamwork) and "My child's other parent believes I am a good parent" (i.e., respect). Statements were rated using a 5-point Likert scale ranging from 1 (strongly agree) to 5 (strongly disagree) with higher scores indicating a stronger, more positive parenting alliance (Konold \& Abidin, 2001). The PAM exhibits high internal consistency with alpha reliability scores for the current sample of $\alpha=.95$ (PAM-CTM), $\alpha=.80$ (PAMFROP), and $\alpha=.96$ (PAM-TOTAL). 


\section{Chapter 4: Results}

Means and standard deviations for the predictor and outcome variables are presented in Table 1. Correlation coefficients were computed among all variables of interest. As evidenced in the table of correlations (see Table 2), the PSI scales were all significantly and positively related to one another; further, the PAM scales were also significantly and positively related to one another and thus, indicating the reliability of these measures. However, the PAM and the co-parenting measure were not correlated with one another, but the PAM and PSI scales were negatively and significantly related to one another.

The co-parenting measure was used to form two co-parenting groups: high and low. The cut-offs for the groups were determined at the $50^{\text {th }}$ percentile, which resulted in the high group consisting of 16 participants and the low group consisting of 15 participants. After the groups were formed, a series of independent t-tests were conducted to determine if the two groups differed on levels of parenting stress and parenting alliance after deployment.

Parenting Alliance Measure. Contrary to the first hypothesis, an independent samples t-test did not reveal significant differences between the groups on parenting alliance following deployment.

Parenting Stress Index/Short Form - Total. Contrary to the second hypothesis, an independent samples t-test did not reveal significant differences between the groups on total parenting stress. A series of post-hoc analyses were then conducted to determine if the groups differed on the subscales of the PSI/SF (Parenting Distress, Parent-Child Dysfunctional Interaction, and Difficult Child). While not significant, the independent 
samples t-test examining differences between the high and low co-parenting groups revealed a trend finding for the PSI-CDI $t(28)=-1.84, p=.08$. Specifically, the low coparenting group reported higher levels of PSI-CDI $(M=20.07 ; S D=7.41)$ than the high co-parenting group $(M=15.87 ; S D=4.85)$. 


\section{Chapter 5: Discussion}

Since the events of September 11, 2001, it is important to investigate the effects that military deployment has on the family because thousands of families are currently facing long-term separation from a spouse or parent. Thus, the purpose of this study was to compare the differences between wives' self-reported parenting alliance and parenting stress after military deployment between two groups: those who reported high coparenting practices during deployment and those who reported low co-parenting practices during deployment. The findings of this study may help researchers and practitioners identify ways to help families experiencing military deployments during the separation as well as during the reintegration periods.

First, it was predicted that the low co-parenting group during deployment would exhibit less parenting alliance post-deployment when compared to the high co-parenting during deployment group. Secondly, it was predicted that the low co-parenting during deployment group would report greater parenting stress post-deployment when compared to the high co-parenting during deployment group. Inconsistent with predictions, the two main hypotheses were not supported in this study. Specifically, the low co-parenting group during deployment did not report less parenting alliance following deployment when compared to the high co-parenting group.

Since almost all of the participants indicated that they experienced more than one deployment $(n=25)$, there may not be differences between the low and high co-parenting groups on the amount of parenting alliance because this sample has the knowledge and skills to better cope with the reintegration of their parenting partner. Thus, co-parenting practices may not influence parenting alliance following deployment, regardless of 
whether they exhibited high or low co-parenting during deployment. For example, Kelley et al. (1994) and Warner et al. (2009) examined the effects of multiple deployments on both the deployed spouse and the stateside spouse. Specifically, Kelley et al. (1994) found that multiple deployments did not impact the reported levels of parenting stress which may indicate that families experiencing multiple deployments have already overcome the stressors associated with first deployments and have established routines for adjusting during the reintegration period of subsequent deployments. It seems likely that families experiencing their first deployments (and subsequent reintegrations) may have more difficulty adjusting than families facing their second or third deployment, and that the level of co-parenting during deployment may impact how they adjust following a first deployment. Therefore, it may be especially important for future researchers to examine the effects of co-parenting on families experiencing their first deployment in order to help develop co-parenting interventions for families experiencing a military deployment whether it is a first or subsequent deployment. For example, programs educating parents on the importance of building strong co-parenting relationships during separation, as well as techniques on how to maintain these positive co-parenting relationships during deployment may serve to help military families cope during the deployment cycle.

In addition, it may be that there were no differences between the two groups in parenting alliance due to sample characteristics. Specifically, previous research studies examining parenting alliance following deployment include populations with a known diagnosed illness. For example, Allen et al. (2010) found that husbands who had recently been deployed exhibited greater PTSD symptoms and less parenting alliance following 
deployment. Thus, it may be important to also consider the formerly deployed spouse's health status when examining adjustment and family dynamics following deployment. Since the current study did not collect information about the well-being or health of the deployed spouse, we have no way of detecting whether or not this would impact the findings. However, the literature indicates it may alter adjustment (e.g., Allen et al., 2010). PTSD may impact co-parenting practices after deployment. Specifically, individuals who suffer from PTSD may exhibit fewer co-parenting practices following their return from deployment. As a result, future studies should examine this unique population identified as experiencing a common mental illness associated with military deployment in order to further help military families who face additional challenges and stressors resulting from deployment.

Furthermore, it may be important to consider that there are differences in the way that individuals co-parent during deployment and following deployment. So, it may not be prudent to examine mean level differences with two different instruments (as was done herein), but rather measure changes on a single instrument of co-parenting in a longitudinal design. This area of study seems important since during deployment parents have to learn how to co-parent while one spouse is away from the family, and then again adjust their co-parenting practices once the deployed spouse returns. This notion is also supported in the literature where studies indicate that during deployment, the stateside spouses have to accept the majority of the parenting roles and responsibilities (Faber et al., 2008; Mmari et al., 2009); however, during the reintegration period, families must renegotiate parenting roles and reestablish rules and routines (Bowling \& Sherman, 2008; Faber et al., 2008; Mmari et al., 2009). Therefore, it seems likely that co-parenting 
behaviors need to be altered during deployment and then again following deployment. As aforementioned, future researchers may address this research question via a longitudinal design and perhaps via qualitative methods to better understand the stability and change of co-parenting goals throughout the deployment cycle.

Similarly, findings did not support the second hypothesis predicting that the low co-parenting group during deployment would exhibit greater parenting stress during the reintegration period than the high co-parenting during deployment group. Specifically, participants in the low co-parenting group did not report significantly greater parenting stress following deployment when compared to the high co-parenting group. However, an examination of the means for the two groups on the PSI- Total, revealed that the low co-parenting group reported higher levels of parenting stress than the high co-parenting group, but they were not significant (see Table 1). Thus, it appears that there are some differences between the two groups in the amount of parenting stress following a deployment. While the findings did not reach significance (likely due to the small sample size, as discussed below), it does give some indication that co-parenting during deployment may protect families from the stress of reintegration; and previous studies do indicate that there are different stressors placed on both the deployed spouse and the stateside spouse (Kelley et al., 1994; Newby et al., 2005), including parenting stress (Bowling \& Sherman, 2008; Faber et al., 2008; Mmari et al., 2009). Thus, co-parenting practices during deployment may serve to reduce or increase parenting stress associated with these challenges during the reintegration period. These trend findings might reach the significance level in a much larger sample. 
Based on the mean differences between the two groups on the total parenting stress scale, post-hoc analyses were conducted to see if the groups differed on the individual subscales of the PSI-SF (Parental Distress, Parent-Child Dysfunctional Interaction, and Difficult Child). These analyses yielded trend findings for one of the subscales; specifically, the low co-parenting group reported higher levels of PSI-CDI than the high co-parenting group. The PSI-CDI scale examines whether the child is meeting parenting expectations and whether or not the parent-child interactions reinforce the parenting role (e.g., “sometimes I feel my child doesn't like me and doesn't want to be close to me"). Thus, it may be that high levels of co-parenting during deployment may be important, especially when parents perceive their relationship with their children to be strained; however this line of reasoning must be approached with caution and requires replication since the finding did not reach significance.

\section{Limitations and Future Directions}

It is important to acknowledge some limitations of the current study. First and foremost, the sample was considerably small; thus, the analyses were underpowered. According to Cohen (1992), in order to detect a medium effect between two independent samples at $\alpha=.05$, data must be gathered from a total of 128 participants ( 64 in each group). This study should be replicated with a larger sample. Moreover, previous studies investigating co-parenting generally comprise at least 70 couples (McConnell \& Kerig, 2002; Ippolito et al., 2010). Trend level findings regarding parenting stress following deployment found in the current study may reach the significance level in a study replicated with a sample consisting of at least 70 parenting couples. 
Additionally, the current sample consisted of single informants who were all females. Future studies should also include father reports of co-parenting practices, parenting alliance, and parenting stress. It would be beneficial to gain insights on how deployment impacts the deployed spouse's feelings of parenting alliance and parenting stress following deployment. It may be that stateside spouses and deployed spouses perceive the impact of deployment on co-parenting and parenting stress differently. For instance, the literature supports the notion that both the stateside and deployed spouses are negatively impacted by deployment; it appears that those negative impacts are qualitatively different for the stateside and deployed spouses. Kelley et al. (1994) found that deployed spouses reported negative consequences of military deployment including increased levels of parenting stress and anxiety. On the other hand, studies of stateside spouses suggest that they experience stresses to include facing parenting responsibilities alone (Henderson, 2008; Sahlstein et al., 2009; SteelFisher et al., 2008) and decreased mental health (SteelFisher et al., 2008; Warner et al., 2009). Thus, it seems fruitful to gain insight from both family members in future studies.

Furthermore, when examining co-parenting practices, it is important to gather information from both parenting partners in order to truly determine co-parenting behaviors within the home (McHale et al., 2002). Because co-parenting refers to two individuals working together to effectively raise and parent their children (McHale et al., 2002), true co-parenting investigations need to involve both parenting partners. Moreover, three of the biological children that the participants referred to while completing the questionnaires were adults (above the age of 19). Thus, the PAM was an inappropriate measure for these participants (the measure is recommended for use with 
children up to 19 years of age). Furthermore, in the United States, the parenting role changes after children become adults (age of 18), thus it is likely that co-parenting adult children differs greatly from co-parenting minor children. As a result, future studies should limit the age of the biological children referred to when completing the surveys to younger than nineteen-years-old.

\section{Conclusions}

Ultimately, the findings of this study may help future researchers to examine the stressors that this unique military population experiences when faced with the deployment of one of the parenting figures. It is important to acknowledge the challenges that the entire family faces when experiencing a deployment, and investigate possible ways to reduce these stressors, such as building and maintaining positive coparenting relationships throughout the entire deployment cycle. Trend level findings of the current study suggest that high co-parenting during deployment is associated with less parenting stress following the deployment. As a result, intervention programs for military families should be developed and implemented in families facing deployment that encourages parents to build and maintain high co-parenting relationships during deployment in order to reduce the amount of parenting stress experienced following the deployment. 


\section{References}

Abidin, R. R. (1990). Parenting Stress Index manual. Charlottesville, VA: Pediatric Psychology Press.

Abidin, R. R., \& Brunner, J. F. (1995). Development of a parenting alliance inventory. Journal of Clinical Child Psychology, 24, 31-40.

Allen, E., Rhoades, G., Stanley, S., \& Markman, H. (2010). Hitting home: Relationships between recent deployment, posttraumatic stress symptoms, and marital functioning for Army couples. Journal of Family Psychology, 24, 280-288.

Assel, M. A., Landry, S. H., Swank, P. R., Steelman, L. L., Miller-Loncar, C. C., \& Smith, K. E. (2002). How do mothers' childrearing histories, stress and parenting affect children's behavioural outcomes?. Child: Care, Health \& Development, 28, 359-368.

Bowling, U., \& Sherman, M. (2008). Welcoming them home: Supporting service members and their families in navigating the tasks of reintegration. Professional Psychology: Research \& Practice, 39, 451-458.

Cohen, J. (1992). A power primer. Psychological Bulletin, 112, 155-159.

Cohen, S., \& Williamson, G. (1988). Perceived stress in a probability sample of the United States. In S. Spacapan \& S. Oskamp (Eds.), The social psychology of health: Claremont Symposium on Applied Social Psychology (31-67). Newbury Park, CA: Sage.

Doyle, M., \& Peterson, K. (2005). Re-entry and reintegration: Returning home after combat. Psychiatric Quarterly, 76, 361-370. 
Eddy, J., Martinez, C., Schiffmann, T., Newton, R., Olin, L., Leve, L., et al. (2008). Development of a multisystemic parent management training intervention for incarcerated parents, their children and families. Clinical Psychologist, 12, 8698.

Faber, A., Willerton, E., Clymer, S., MacDermid, S., \& Weiss, H. (2008). Ambiguous absence, ambiguous presence: A qualitative study of military reserve families in wartime. Journal of Family Psychology, 22, 222-230.

Feinberg, M. E. (2003). The internal structure and ecological context of coparenting: A framework for research and intervention. Parenting: Science and Practice, 3, 95131.

Guajardo, N. R., Snyder, G., \& Petersen, R. (2009). Relationships among parenting practices, parental stress, child behaviour, and children's social-cognitive development. Infant \& Child Development, 18, 37-60.

Henderson, S. (2008). Military MOMS DADS. Ebony, 63, 184-188.

Hill, R. (1949). Families under stress: Adjustment to the crises of war separation and return. New York: Harper \& Brothers.

Hock, E., McBride, S., \& Gnezda, M. T. (1989). Maternal separation anxiety: Motherinfant separation from the maternal perspective. Child Development, 60, 793-802.

Houck, K. F., \& Loper, A. B. (2002). The relationship of parenting stress to adjustment among mothers in prison. American Journal of Orthopsychiatry, 72, 548-558. 
Ippolito Morrill, M., Hines, D., Mahmood, S., \& Cordova, J. (2010). Pathways between marriage and parenting for wives and husbands: The role of coparenting. Family Process, 49, 59-73.

Kelley, M., Herzog-Simmer, P., \& Harris, M. (1994). Effects of military-induced separation on the parenting stress and family functioning of deploying mothers. Military Psychology, 6, 125-138.

Konold, T. R., \& Abidin, R. R. (2001). Parenting alliance: A multifactor perspective. Assessment, 8, 47-65.

Kroenke K., Spitzer R. L., \& Williams J. W. (2001). The PHQ-9: validity of a brief depression severity measure. Journal of General Internal Medicine, 16, 606-613.

McHale, J. P. (1997). Overt and covert coparenting processes in the family. Family Process, 36, 183-201.

McHale, J., Khazan, I., Erera, P., Rotman, T., DeCourcey, W., \& McConnell, M. (2002). Coparenting in diverse family systems. In M. H. Bornstein (Ed.), Handbook of parenting ( $2^{\text {nd }}$ ed.) (pp. 75-100). Mahwah, NJ: Lawrence Erlbaum Associates. McHale, J. P., Kuersten-Hogan, R., \& Rao, N. (2004). Growing points for coparenting theory and research. Journal of Adult Development, 11, 221-234.

McConnell, M., \& Kerig, P. (2002). Assessing coparenting in families of school-age children: Validation of the coparenting and family rating system. Canadian Journal of Behavioural Science, 34, 44-58.

Mmari, K., Roche, K., Sudhinaraset, M., \& Blum, R. (2009). When a parent goes off to war: Exploring the issues faced by adolescents and their families. Youth \& Society, $40,455-475$. 
Modecki, K., \& Wilson, M. (2009). Associations between individual and family level characteristics and parenting practices in incarcerated African American fathers. Journal of Child \& Family Studies, 18, 530-540.

Moos, R. H., \& Moos, B. (1981). Revised family environment scale. Palo Alto, CA: Consulting Psychologists Press.

Newby, J., McCarroll, J., Ursano, R., Fan, Z., Shigemura, J., \& Tucker-Harris, Y. (2005). Positive and negative consequences of a military deployment. Military Medicine, $170,815-819$.

Power, T. G. (1991). Parenting dimensions inventory. Unpublished manuscript, University of Houston.

Sahlstein, E., Maguire, K., \& Timmerman, L. (2009). Contradictions and praxis contextualized by wartime deployment: Wives' perspectives revealed through relational dialectics. Communication Monographs, 76, 421-442.

Schumm, W. R., Bell, D., Knott, B., \& Rice, R. E. (1996). The perceived effect of stressors on marital satisfaction among civilian wives of enlisted soldiers deployed to Somalia for Operation Restore Hope. Military Medicine, 161, 601606.

Slater, M. A., \& Power, T. G. (1987). Multidimensional assessment of parenting in single-parent families. Advances in family intervention. Assessment and Theory, 4, 197-228.

SteelFisher, G., Zaslavsky, A., \& Blendon, R. (2008). Health-related impact of deployment extensions on spouses of active duty army personnel. Military Medicine, 173, 221-229. 
Tuerk, E., \& Loper, A. (2006). Contact between incarcerated mothers and their children: Assessing parenting stress. Journal of Offender Rehabilitation, 43, 23-43.

Van Egeren, L. A., \& Hawkins, D. P. (2004). Coming to terms with coparenting: implications of definition and measurement. Journal of Adult Development, $11,165-178$.

Wadsworth, S. (2010). Family risk and resilience in the context of war and terrorism. Journal of Marriage and Family, 72, 537-556.

Warner, C., Appenzeller, G., Warner, C., \& Grieger, T. (2009). Psychological effects of deployments on military families. Psychiatric Annals, 39, 56-63. 
Table 1

Means and Standard Deviations

\begin{tabular}{|c|c|c|c|c|c|}
\hline Variable & $M$ & $S D$ & Minimum & Maximum & $N$ \\
\hline \multicolumn{6}{|l|}{ Total Sample } \\
\hline Co-Parenting & 17.71 & 3.85 & 9.00 & 21.00 & 31 \\
\hline Parenting stress -TOTAL & 70.46 & 18.50 & 46.00 & 108.00 & 30 \\
\hline Parenting stress - PD & 23.53 & 8.44 & 12.00 & 43.00 & 30 \\
\hline Parenting stress $-\mathrm{CDI}$ & 17.97 & 6.52 & 12.00 & 34.00 & 30 \\
\hline Parenting stress $-\mathrm{DC}$ & 28.96 & 6.54 & 20.00 & 43.00 & 30 \\
\hline Parenting alliance measure & 88.45 & 10.53 & 63.00 & 100.00 & 31 \\
\hline \multicolumn{6}{|l|}{ High Co-Parenting Group } \\
\hline Parenting stress -TOTAL & 66.23 & 19.23 & & & 15 \\
\hline Parenting stress - PD & 22.33 & 8.73 & & & 15 \\
\hline Parenting stress $-\mathrm{CDI}$ & 15.87 & 4.85 & & & 15 \\
\hline Parenting stress $-\mathrm{DC}$ & 28.07 & 6.95 & & & 15 \\
\hline Parenting alliance measure & 88.00 & 11.77 & & & 16 \\
\hline \multicolumn{6}{|l|}{ Low Co-Parenting Group } \\
\hline Parenting stress - TOTAL & 74.66 & 17.36 & & & 15 \\
\hline Parenting stress - PD & 24.73 & 8.25 & & & 15 \\
\hline Parenting stress $-\mathrm{CDI}$ & 20.07 & 7.41 & & & 15 \\
\hline Parenting stress DC & 29.86 & 6.21 & & & 15 \\
\hline Parenting alliance measure & 88.93 & 9.42 & & & 15 \\
\hline
\end{tabular}


Table 2

Correlations Between Co-Parenting, Parenting Stress, and Parenting Alliance

\begin{tabular}{|c|c|c|c|c|c|c|}
\hline Measure & 1. & 2. & 3. & 4. & 5. & 6. \\
\hline 1. Co-parenting during deployment & -- & -.03 & -.03 & -.05 & .02 & -.07 \\
\hline 2. Parenting stress - TOTAL & & -- & $.88^{* *}$ & $.83^{* *}$ & $.86^{* *}$ & $-.64 * *$ \\
\hline 3. Parenting stress $-\mathrm{PD}$ & & & -- & $.57 * *$ & $.63 * *$ & $-.65 * *$ \\
\hline 4. Parenting stress $-\mathrm{CDI}$ & & & & -- & $.62 * *$ & $-.45 *$ \\
\hline 5. Parenting stress $-\mathrm{DC}$ & & & & & -- & $-.52 * *$ \\
\hline 6. Parenting alliance measure & & & & & & -- \\
\hline
\end{tabular}

$* * p<.01 ; * p<.05$ (two-tailed) 


\section{Appendix A}

\section{Background/Demographics Questionnaire}

What is today's date?

\section{Participant's Gender:}

Male

Female

\section{Participant's Age:}

\section{Participant's Race:}

American Indian/Alaska Native

Asian

Black or African American

Native Hawaiian or Other Pacific Islander

$\square$ White or Caucasian

Bi- or Multi-racial (please specify):

$\square$ Other (please specify):

\section{Participant's Ethnicity:}

Hispanic or Latino

$\square \quad$ Not Hispanic or Latino

Participant's Education level (please select highest level)

Elementary School

High School

Vocational School

Some College

University Degree

Some Graduate School

Master's Degree

Doctoral Degree

\section{Participant's Occupation Status}

Employed full-time

Employed part-time

Not employed outside of home

Retired

Unemployed and seeking employment

Other (specify) 
Where do you currently reside?

-Northeast, Division 1 (New England) Maine, New Hampshire, Vermont, Massachusetts, Rhode Island, Connecticut

-Northeast, Division 2 (Mid-Atlantic) New York, Pennsylvania, New Jersey

-Midwest, Division 3 (East North Central) Wisconsin, Michigan, Illinois, Indiana, Ohio

-Midwest, Division 4 (West North Central) Missouri, North Dakota, South Dakota,

Nebraska, Kansas, Minnesota, Iowa

-South, Division 5 (South Atlantic) Delaware, Maryland, District of Columbia, Virginia,

West Virginia, North Carolina, South Carolina, Georgia, Florida

-South, Division 6 (East South Central) Kentucky, Tennessee, Mississippi, Alabama

-South, Division 7 (West South Central) Oklahoma, Texas, Arkansas, Louisiana

-West, Division 8 (Mountain) Idaho, Montana, Wyoming, Nevada, Utah, Colorado, Arizona, New Mexico

-West, Division 9 (Pacific) Alaska, Washington, Oregon, California, Hawaii

-Do not reside in the United States

\section{Household Income:}

Less than $\$ 10,000$

$\$ 10,000-\$ 25,000$

$\$ 25,000-\$ 50,000$

$\$ 75,000-\$ 100,000$

$\$ 100,000$ - $\$ 150,000$

Greater than $\$ 150,000$

Prefer not to answer

I am the spouse of someone who was deployed.

Yes

No

How many military deployments have you and your spouse experienced?

1

2-3

$4-5$

$6+$

What branch of the military is your spouse in?

Air Force

Army

Marines

Navy

The National Guard

How long ago did your spouse return from deployment?

Within the last 6 months

7-12 months ago

Over a year ago 
How long was the most recent military deployment?

My formerly deployed spouse and I have at least one biological child.

Yes

No

How many biological children do you and your formerly deployed spouse have?
1
2
3
4
$5+$

Please list the age and gender of your biological children with your military spouse. DO NOT LIST NAMES

Please list the age and gender of any other children living in the home with you and indicate whether they are step-children, foster children, adoptive, or other (specify). DO NOT LIST NAMES.

The following three questionnaires require you to answer questions regarding one of your biological children with your spouse that experienced military deployment. Please describe the gender and age of the biological child you will be referencing while responding to each of the following questionnaires. DO NOT LIST YOUR CHILD'S NAME. 


\title{
Appendix B
}

\author{
The Coparenting Scale
}

McHale (1997)

Instructions. Please answer the questions based on your experiences while your spouse was deployed (during separation from your spouse). Complete the questions with reference to the particular child you indicated on the demographics questionnaire. Answer each question based on how frequently you engaged in each activity including "0" Absolutely Never through "7" Almost Constantly.

How often in a typical week do you:

1. Show affection (a hug or kiss) to your child?

2. Show affection (a hug or kiss) to your partner?

3. Make an affirming or complimentary remark about your child to your partner?

4. Make an affirming or complimentary remark about your partner to your child?

5. Say or do something to invite, facilitate, or promote an affectionate or pleasant interchange between your partner and your child (e.g., "Show mom" or "Let dad play")?

6. Take the lead in setting a limit or disciplining your child?

7. Request that your partner set a limit or discipline your child?

8. Take a "back seat" while your partner deals with your child's negative behavior?

9. "Undo" or oppose a punishment or limit your partner has set with your child?

10. Find yourself in a mildly tense or sarcastic interchange with your partner?

11. Argue with your partner?

How often in a typical week (when you are alone with your child) do you:

12. Say something to your child about the parenting dyad ("mommy and daddy...") or family triad or group ("we all ...")?

13. Make a comment to enhance your child's mental image of your absent partner ("e.g., "Daddy loves you"; "Mommy is proud of you")?

14. Make a remark to invoke or include the absent parent ("Dad will be home soon"; "You should show that to mom")?

15. Make a comment about your partner that might create a somewhat negative feeling state in your child (e.g., "Dad gets mad when you do that"; "I don't think mom would like that")?

16. Find yourself saying something clearly negative or disparaging about your partner to your child? 


\section{Appendix C}

\section{Parenting Stress Index/ Short Form \\ Instructions}

This questionnaire contains 36 statements. Read each statement carefully. Please respond to the statements based on your feelings now (since your deployed spouse has returned). Again, for each statement, please focus on the particular child you indicated on the demographics questionnaire, and click the response that best represents your opinion.

Click SA if you strongly agree with the statement.

Click $\mathbf{A}$ if you agree with the statement.

Click NS if you are not sure.

Click $\mathbf{D}$ if you disagree with the statement.

Click SD if you strongly disagree with the statement.

For example, if you sometimes enjoy going to the movies, you would circle $\mathbf{A}$ in response to the following statement:

I enjoy going to the movies. SA A NS D SD

While you may not find a response that exactly states your feelings, please click the response that comes closest to describing how you feel. YOUR FIRST REACTION TO EACH QUESTION SHOULD BE YOUR ANSWER.

Click only one response for each statement, and respond to all statements.

\section{SA = Strongly Agree $\quad A=$ Agree $\quad$ NS $=$ Not Sure \\ $\mathrm{D}=$ Disagree $\mathrm{SD}=$ Strongly Disagree}

1. I often have the feeling that I cannot handle things very well.

SA A NS D SD

2. I find myself giving up more of my life to meet my children's needs than I ever expected.

SA A NS D SD

3. I feel trapped by my responsibilities as a parent.

SA A NS D SD

4. Since having this child, I have been unable to do new and different things.

SA A NS D SD

5. Since having a child, I feel that I am almost never able to do things that I like to do.

SA A NS D SD

6. I am unhappy with the last purchase of clothing I made for myself.

SA A NS D SD 
7. There are quite a few things that bother me about my life.

SA A NS D SD

8. Having a child has caused more problems than I expected in my relationship with my spouse (or male/female friend).

SA A NS D SD

9. I feel alone and without friends.

SA A NS D SD

10. When I go to a party, I usually expect not to enjoy myself.

SA A NS D SD

11. I am not as interested in people as I used to be.

SA A NS D SD

12. I don't enjoy things as used to.

SA A NS D SD

13. My child rarely does things for me that make me feel good.

SA A NS D SD

14. Sometimes I feel my child doesn't like me and doesn't want to be close to me.

SA A NS D SD

15. My child smiles at me much less than I expected.

SA A NS D SD

16. When I do things for my child, I get the feeling that my efforts are not appreciated very much.

SA A NS D $\quad$ SD

17. When playing, my child doesn't often giggle or laugh.

SA A NS D SD

18. My child doesn't seem to learn as quickly as most children.

SA A NS D SD

19. My child doesn't seem to smile as much as most children.

SA A NS D SD

20. My child is not able to do as much as I expected.

SA A NS D SD

21. It takes a long time and it is very hard for my child to get used to new things.

SA A NS D SD 
For the next statement, choose your response from the choices " 1 " to " 5 " below.

22. I feel that I am: 1 . not very good at being a parent

2. a person who has some trouble being a parent

3. an average parent

4. a better than average parent

5. a very good parent

$\begin{array}{lllll}1 & 2 & 3 & 4 & 5\end{array}$

23. I expected to have closer and warmer feelings for my child than I do and this bothers me.

SA A NS D $\quad$ SD

24. Sometimes my child does things that bother me just to be mean.

SA A NS D SD

25. My child seems to cry or fuss more often than most children.

SA A NS D SD

26. My child generally wakes up in a bad mood.

SA A NS D SD

27. I feel that my child is very moody and easily upset.

SA A NS D SD

28. My child does a few things which bother me a great deal.

SA A NS D SD

29. My child reacts very strongly when something happens that my child doesn't like.

SA A NS D SD

30. My child gets upset easily over the smallest thing.

SA A NS D SD

31. My child's sleeping or eating schedule was much harder to establish than I expected.

SA A NS D SD

For the next statement, choose your response from the choices " 1 " to "5" below.

32. I have found that getting my child to do something or stop doing something is:

$\begin{array}{lllll}1 & 2 & 3 & 4 & 5\end{array}$

1. much harder than I expected

2. somewhat harder than I expected

3. about as hard as I expected

4. somewhat easier than I expected

5. much easier than I expected 
For the next statement, choose your response from the choices " $10+$ " to "1-3".

33. Think carefully and count the number of things which your child does that bother you. $10+\quad 8-9 \quad 6-7 \quad 4-5 \quad 1-3$

For example: dawdles, refuses to listen, overactive, cries, interrupts, fights, whines, etc.

34. There are some things my child does that really bother me a lot.

SA A NS D SD

35. My child turned out to be more of a problem than I had expected.

SA A NS D SD

36. My child makes more demands on me than most children.

SA A NS D SD 


\section{Appendix D}

Parenting Alliance Measure (PAM)

R. R. Abidin

Instructions: Please rate the following statements using the rating scale of " 5 " Strongly Agree to "1" Strongly Disagree based on your feelings now (when your spouse has returned to the family from deployment). The questions listed below concern what happens between you and your child's other parent involved in the care of your child. Again, please complete the questions focusing on the particular child you previously indicated on the demographics questionnaire. Although you may not find an answer that exactly describes what you think, please choose the answer that comes closest to what you think. YOUR FIRST REACTON SHOULD BE YOUR ANSWER.

Example:

Strongly Agree 5

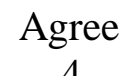

4
Not Sure

3
Disagree
Strongly Disagree

1

My child's other parent and I go to the movies. (If you sometimes go to the movies, you would circle "4.")

1. My child's other parent enjoys being alone with our child.

2. During pregnancy, my child's other parent expressed confidence in my ability to be a good parent.

3. When there is a problem with our child, we work out a good solution together.

4. My child's other parent and I communicate well about our child.

5. My child's other parent is willing to make personal sacrifices to help take care of our child.

6. Talking to my child's other parent about our child is something I look forward to.

7. My child's other parent pays a great deal of attention to our child.

8. My child's other parent and I agree on what our child should and should not be permitted to do.

9. I feel close to my child's other parent when I see him/her play with our child.

10. My child's other parent knows how to handle children well. 
11. My child's other parent and I are a good team.

12. My child's other parent believes I am a good parent.

13. I believe my child's other parent is a good parent.

14. My child's other parent makes my job of being a parent easier.

15. My child's other parent sees our child in the same way I do.

16. My child's other parent and I would basically describe our child in the same way.

17. If our child needs to be punished, my child's other parent and I usually agree on the type of punishment.

18. I feel good about my child's other parent's judgment about what is right for our child.

19. My child's other parent tells me I am a good parent.

20. My child's other parent and I have the same goals for our child. 